\title{
O discurso real e o discurso ideal de professores de Educação Física do ensino superior sobre docência
}

\author{
Rudney da Silva * \\ Alexandro Andrade** \\ José Carlos Zanelli ***
}

\begin{abstract}
Resumo: Este estudo teve como objetivo analisar a relação entre o discurso real e o discurso ideal de professores de Educação Física de ensino superior sobre docência, oriundos das universidades públicas do Estado de Santa Catarina, Brasil. Os participantes foram selecionados através de critérios relacionados aos sujeitos e às instituições, totalizando 16 dos 27 indivíduos previamente identificados. Os dados foram coletados por meio de entrevistas semi-estruturadas e recorrentes, e analisados através da análise de conteúdo. Foi verificado o predomínio dos aspectos que afastam o discurso ideal do discurso real, principalmente àqueles associados ao produtivismo, tais como competitividade, individualismo, desvalorização, condições desfavoráveis, ambientes competitivos, fatores mercadológicos, e objetivos econômicos.
\end{abstract}

Palavras-Chave: Docentes. Educação Física e treinamento. Ensino superior.

\footnotetext{
*Licenciado em Educação Física. Especialista em Educação Física Escolar e em Atividade Motora Adaptada. Mestre em Ciências do Movimento Humano. Doutor em Engenharia de Produção. Professor adjunto da Universidade do Estado de Santa Catarina. Líder do Grupo de Estudos e Pesquisa em Atividade Motora Adaptada/CNPQ e coordenando o Laboratório de Atividade Motora Adaptada/CEFID/UDESC. Florianópolis, SC, Brasil. E-mail: rudney@udesc.br ${ }^{* *}$ Graduado em Educação Física. Especialista em Treinamento Desportivo. e Psicologia do Esporte e Aprendizagem Motora. Mestre em Educação Física e em Psicologia. Doutor em Engenharia de Produção. Professor da Graduação, Mestrado e Doutorado do Centro de Ciências da Saúde e do Esporte (CEFID) da Universidade do Estado de Santa Catarina (UDESC). Coordenador do Laboratório de Psicologia do Esporte e do Exercício - LAPE. Diretor Científico do Colégio Brasileiro de Ciências do Esporte - CBCE. Florianópolis, SC, Brasil. E-mail: d2aa@udesc.br

*** Graduado em Psicologia. Especialista em Psicologia Organizacional e do Trabalho. Mestre em Psicologia Social das Organizações. Doutor em Educação. Pós-doutorado com foco nas ações de uma gestão estratégica, nas teorias e tratamento do estresse nas organizações de trabalho. Professor associado no Departamento de Psicologia da Universidade Federal de Santa Catarina. Florianópolis, SC, Brasil. E-mail: jczanelli@terra.com.br
} 


\section{INTRODUÇÃO}

A universidade passa por uma crise que afeta sua existência. Desde seu surgimento no século XII a universidade tem buscado conhecimentos críticos aos modelos hegemônicos, os quais têm proporcionado significativa legitimidade social a esta instituição (SINGER, 1994; CHAUÍ, 2001). Porém, análises epistemológicas demonstram que a universidade tem sofrido imposições que comprometem sua essência, das quais se destaca a excessiva influência do sistema econômico sobre a produção de conhecimentos. (BUNGE, 1980; COSTA et al., 1996; SGUISSARDI, 2000; SILVA JÚNIOR, 2009).

Silva Júnior, Sguissardi e Silva (2010) apontam que o sistema econômico tem atribuído à universidade a responsabilidade pela formação profissional e produção científica e tecnológica ligadas ao produtivismo que modifica radicalmente a natureza institucional e docente. Este fenômeno provoca conflitos entre o custeamento da universidade e a autonomia do saber, pois não favorece a produção de conhecimentos capazes de mudar o modo produtivista em favor da coletividade, relegando os conhecimentos críticos a planos secundários e afetando a maioria das áreas de formação do ensino superior brasileiro (BUNGE, 1980; MARTINS, 2008; RABELO, 2010).

Bianchetti (2009) ao analisar a produção científica nas ciências do esporte, aponta que nas três últimas décadas ocorreu uma apropriação do esporte e da atividade física para servir às finalidades do capital em crise, identificando diversos problemas associados ao produtivismo universitário presentes na Educação Física, tais como, predomínio da área biomédica sobre a pedagógica e social, acirramento do embate entre formação humana e treinamento esportivo de alto nível, e fragmentação da formação universitária. Acrescentam-se ainda, as influências médico-higienistas orientadas pelo discurso sanitarista que negligencia as mudanças econômicas, políticas, sociais relacionadas à saúde e provoca distorções sociais e científicas (PAIM; ALMEIDA FILHO, 1998; MENDES; NÓBREGA, 2008). 
Deste modo, verifica-se que as imposições produtivistas provocam influências no discurso acadêmico que o afastam gradativamente da realidade social (IANNI, 1986; DE TOMASI; WARDE; HADDAD, 1998; CHAUÍ, 2001). Portanto, investigações que identifiquem distorções entre os conhecimentos produzidos na universidade e as demandas sociais requeridas podem contribuir ao ensino superior, já que a função da universidade extrapola a formação profissional. (MOREIRA; TOJAL, 2009). Considerando o exposto, este artigo tem como objetivo principal analisar a relação entre o discurso real e o discurso ideal de professores de Educação Física de ensino superior sobre docência, oriundos das universidades públicas do Estado de Santa Catarina, Brasil.

\section{Aspectos Metodológicos}

\subsection{Caracterização do ESTUdo}

Este artigo foi caracterizado como exploratório, descritivo, e de campo, realizado através de procedimentos quantitativos e qualitativos de coleta e análise das informações (LAVILLE; DIONNE, 1999; ALVES-MAZZOTI; GEWANDSZNAJDER, 2002). Todos os procedimentos foram previamente aprovados por um Comitê de Ética em Pesquisas (Protocolo 112/2004/CEPSH/UDESC), como parte de uma pesquisa de doutorado (SILVA, 2006).

\subsection{PARTICIPANTES}

Os participantes foram previamente identificados a partir dos seguintes critérios de seleção: a) pertencer à universidade pública catarinense que oferecesse curso de Educação Física e permitisse livre acesso às informações; b) ter graduação em Educação Física; c) ter titulação de doutor; d) ter estabilidade profissional; e) atuar no curso de Educação Física; f) participar do estudo de forma livre e consentida.

Justifica-se a escolha da Educação Física por caracterizar-se como uma área de formação que apresenta especificidades que 
necessitam de investigações, assim como de um nível de qualificação que considere a capacidade doutoral de produção de valores normativos que marcam seus referenciais teóricos, mas que são indivíduos igualmente suscetíveis ao produtivismo acadêmico existente em Educação Física. Justifica-se ainda a escolha por servidores públicos estáveis de universidades que permitissem livre acesso e participação livre e consentida, pela necessidade de garantir os cuidados éticos imprescindíveis à pesquisa científica.

O levantamento amostral identificou que, com exceção da intenção de participar do estudo, $27(\mathrm{~N})$ professores atendiam aos critérios de seleção em duas instituições (01 federal; 01 estadual). Após a identificação dos participantes, procedeu-se o sorteio aleatório de 14 professores respondentes e mais dois professores para o estudo piloto, totalizando 16 sujeitos (n) que consentiram integralmente em participar do estudo.

\subsection{QUADRO OPERACIONAL}

A elaboração do quadro operacional com indicadores da pesquisa permite a passagem da linguagem abstrata do discurso para a linguagem concreta, e possibilita a interpretação dos fundamentos teóricos do trabalho (LAVILLE; DIONNE, 1999). Assim, os indicadores foram agrupados em categorias, subcategorias e temas conforme Figura 1.

\begin{tabular}{|c|c|c|}
\hline CATEGORIA & SUBCATEGORIAS & TEMAS \\
\hline \multirow{3}{*}{$\begin{array}{l}\text { Discursos sobre } \\
\text { Docência no } \\
\text { Ensino superior em } \\
\text { Educação Física }^{a}\end{array}$} & $\begin{array}{l}\text { Produtivismo e } \\
\text { Docência } \\
\text { Universitáriaa }^{\text {Univis }}\end{array}$ & $\begin{array}{l}\text { Competitividade }{ }^{\mathrm{b}} ; \text { Individualismo } o^{\mathrm{b}} \text {; Status } \\
\text { acadêmico }^{\mathrm{a}, \mathrm{b}} \text {; Condições salariais }{ }^{\mathrm{a}, \mathrm{b}} ; \text { Ambiente } \\
\text { acadêmico }^{\mathrm{a}, \mathrm{b}} ; \text { Fatores mercadológicos }^{\mathrm{b}} ; \text { Objetivos } \\
\text { universitários econômicos }{ }^{\mathrm{b}} \text {. }\end{array}$ \\
\hline & $\begin{array}{l}\text { Afastamento entre } \\
\text { Teoria e Prática }{ }^{a}\end{array}$ & 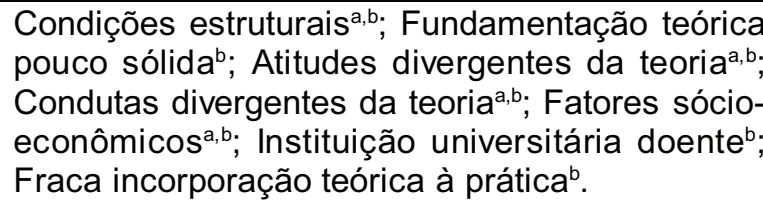 \\
\hline & $\begin{array}{l}\text { Aproximação entre } \\
\text { Teoria e Prática }^{a}\end{array}$ & $\begin{array}{l}\text { Saúde sob enfoque orgânico a,b; Hegemoneidade } \\
\text { paradigmática }{ }^{a, b} \text {; Vulgarização do discurso em } \\
\text { saúde }^{\mathrm{b}} \text {; Legalidade do discurso em saúde }{ }^{\mathrm{b}} \text {; Bases } \\
\text { empíricas da atuação docente }^{\mathrm{b}} \text {. }\end{array}$ \\
\hline
\end{tabular}

a:Definido a priori; ${ }^{\mathrm{b}}$ : Definido a posteriori.

Figura 1. Quadro operacional da pesquisa.

Wovimento, Porto Alegre, v. 16, n. 03, p. 133-154, julho/setembro de 2010. 
Os estudos qualitativos exigem flexibilidade na composição dos indicadores a priori, permitindo a inserção a posteriori de conteúdos significativos ao desenvolvimento da pesquisa. Deste modo, as categorias a posteriori possibilitam o reconhecimento da realidade investigada e o avanço à literatura especializada. (LAVILLE; DIONNE, 1999).

\subsection{Procedimentos E INSTRUMENTOS}

Os dados numéricos foram coletados através de questionário construído e validado em estudo-piloto, composto de questões sobre informações sócio-demográficas, pedagógicas e ocupacionais, tais como idade, sexo, formação, qualificação, alunado, turmas, atuação (graduação; pós-graduação), jornada, entre outros.

Os dados verbais foram coletados através de entrevistas semiestruturadas, construídas e validadas em estudo-piloto, compostas de roteiro sobre as seguintes temáticas: a) condições de trabalho na universidade (jornada, estrutura física, recursos materiais, salário); b) carreira docente (condição sócio-econômica, status profissional, função social); c) promoção da saúde e docência no ensino superior em Educação Física. Utilizou-se ainda, entrevistas recorrentes visando clarear e aprofundar o conteúdo das entrevistas, permitindo diminuir distorções entre o conteúdo coletado e o interpretado, aumentando a confiabilidade das informações e identificando aspectos significativos não previstos previamente. $O$ roteiro das recorrências somente foi definido após a análise dos conteúdos, a qual identificou os significados do fenômeno investigado (ZANELLI, 2002).

Os dados foram coletados e codificados (P1 a P16) após o recolhimento do termo de consentimento livre e esclarecido. Os questionários foram aplicados concomitantemente à realização das entrevistas, conforme local, data e horário previamente agendado pelos envolvidos. Os participantes responderam integralmente as questões propostas nos instrumentos. As devolutivas foram realizadas aos sujeitos que a solicitaram. 


\subsection{APRESENTAÇÃO E ANÁLISE DOS DADOS}

Os dados numéricos foram tratados por meio da estatística descritiva através do cálculo da medida mediana $(\mathrm{Md})$ e apresentados através de freqüências simples (f). (ALVES-MAZZOTI; GEWANDSZNAJDER, 2002). Os dados verbais foram tratados através da análise de conteúdo e da técnica do espelho. A análise de conteúdo foi realizada através da técnica da análise categorial que após a codificação e sistematização dos dados verbais procedeu à seleção das informações, categorizando os conteúdos em blocos temáticos. As categorias principais foram obtidas através da identificação e seleção das unidades de significância, as quais englobaram e mediaram os indicadores no discurso, sem, no entanto, perder a visão integral do discurso (BARDIN, 2000). A técnica do espelho expôs lado a lado as categorias oriundas do discurso real dos participantes e do discurso ideal extraído da literatura, as quais foram sistematizadas nos quadros-síntese, buscando-se não estabelecer comparações, mas contrapontos passíveis de provocar o debate (ANDRADE, 2003).

Os resultados foram organizados e apresentados em quatro eixos norteadores: a) Caracterização dos participantes; b) Produtivismo e docência universitária; c) Afastamento entre teoria e prática; e d) Aproximação entre teoria e prática. Esta organização baseia-se no cuidado ético de respeitar as dicotomias implícitas no discurso analisado e permitir a argumentação tanto dialógica, quanto analógica destes discursos, principalmente pelas similaridades relativas plausíveis de demonstrar suas orientações principais (SMALING, 2002). Este procedimento foi ratificado pelos sujeitos que explicitaram a necessidade de considerar que são doutos conhecedores das temáticas investigadas, conferindo deste modo, embora respeitando as dicotomias, confiabilidade aos dados. 


\section{ANÁLISE DAS INFORMAÇÕES}

\subsection{CARACTERIZAÇÃO DOS PARTICIPANTES}

Os dados numéricos demonstraram que a maioria dos participantes é do sexo masculino $(\mathrm{f}=14)$, pertencente à instituição federal $(\mathrm{f}=11)$, atuante na graduação $(\mathrm{f}=16)$ e na pós-graduação $(\mathrm{f}=12)$, e que trabalha nos três turnos $(\mathrm{f}=7)$, possui jornada de 40 horas/semana $(\mathrm{f}=14)$ com dedicação exclusiva $(\mathrm{f}=14)$. A análise dos dados sócio-demográficos, pedagógicos e ocupacionais apontou valores de medida mediana de 47,5 anos de idade, 24,5 anos de graduação, 05 anos de doutoramento, 13,5 anos de docência universitária, 70 alunos e 03 turmas por semestre. O levantamento das funções administrativas identificou os seguintes cargos ocupados pelos participantes: Reitor (P15), Diretor de centro (P1/P6), Coordenador de pós-graduação (P5/P9), Coordenador de graduação (P12), Chefe de departamento (P4), Coordenador de laboratório (P1/P2/P3/P5/ P6/P10/P12/P13/P15/P16) e Editor científico (P12/P16)

O levantamento das cadeiras ministradas pelos participantes apontou as seguintes disciplinas: metodologia da pesquisa (P1/P2/ $\mathrm{P} 14 / \mathrm{P} 15)$, aprendizagem motora (P1/P4/P5), pedagogia (P1/P2/P12), desenvolvimento motor (P4/P5/P10), cinesiologia (P4/P6/P13), psicologia (P1/P4), esportes (P3/P5), treinamento esportivo (P4/P9), biomecânica (P6/P15), voleibol (P7/P11), atividade física e saúde (P9/P11), natação (P11/13), antropologia (P8), biodinâmica (P16), gerontologia $(\mathrm{P} 2)$, prática de ensino $(\mathrm{P} 3)$, judô $(\mathrm{P} 4)$, medidas e avaliação (P4), educação física escolar (P5), atletismo (P7), ginástica (P8), sociologia, (P8), condicionamento físico (P9), psicomotricidade (P10), handebol (P11), educação física e mídia (P12), introdução à educação física (P12), recreação e lazer (P14).

\subsection{PRODUTIVISMO E DOCÊNCIA UNIVERSITÁRIA}

A partir das análises de conteúdo sobre os resultados verbais dos participantes, verificou-se que a docência universitária está associada ao produtivismo acadêmico, principalmente pelas conseqüências 
inerentes à competitividade e ao individualismo sobre o status docente, o ambiente acadêmico, os objetivos institucionais e a manutenção e legitimidade da universidade. Identificou-se ainda, que a responsabilidade por esta situação está associada majoritariamente ao modelo político e econômico hegemônico.

A competitividade típica do modelo político e econômico hegemônico torna-se responsável pelos prejuízos às questões éticas, à medida que o produtivismo suplanta os aspectos inerentes à condição humana, como solidariedade, coletividade, dignidade, entre outros, independentemente da condição ocupacional dos indivíduos, provocando conseqüências a diversos aspectos da realidade universitária atual, como sugere o Participante 14 que "[...] por mais ético que você seja, [a competitividade] afeta você". Entretanto, alguns participantes entendem que esta responsabilidade centra-se nos comportamentos individuais.

Júnior, Sguissardi e Silva (2010) analisam que o pólo antitético da reestruturação produtiva se refere à utilização dos fundos públicos pelo capital, reformando as instituições sociais e provocando mudanças radicais à docência universitária. Lemos (2010) afirma ainda, que o produtivismo acadêmico restringe a dimensão interrogativa e crítica do trabalho docente, retirando a política e a ética da formação profissional. Neste contexto, Sobral e Ramos (2010) demonstram que a lógica de mercado modifica gradativamente o ethos acadêmico através da competitividade aplicada ao ambiente acadêmico.

O status acadêmico, apesar de ser considerado favorável ao trabalho docente pela possibilidade de influência nos futuros profissionais que estão sendo formados na universidade, vem sendo gradativamente diminuído, como observa o Participante 3: "A atuação de um professor doutor é algo fabuloso, por que se torna referência, não só acadêmica mas na sociedade, mesmo que esta referência ao longo do tempo venha sendo perdida". Contudo, alguns participantes com mais de 15 anos de docência entendem que o status acadêmico ainda pode ser considerado socialmente muito forte e que as ações individuais deveriam ser revisadas. Costa et al., 
(1996, p.20) revelam que existem diversos pontos problemáticos ao status profissional da docência em Educação Física, destacando-se o controle político de um campo de ação e de discurso conquistado por determinado grupo social, em certo momento histórico.

A diminuição do status acadêmico ocorre fundamentalmente pela desvalorização profissional, sobretudo pelo declínio salarial que impõe condições que dificultam o desempenho e o desenvolvimento dos professores universitários, pois restringe as condições de procura pelo conhecimento, como aponta o Participante 10 que "o status profissional da carreira do magistério, até pelos salários, não é nada, e isso repercute muito na sociedade, $[. .$.$] de maneira geral ser pro-$ fessor universitário hoje, não significa mais nada [...]", e o Participante 13 que afirma que "o status social está diretamente relacionado com o salário [...], e o status profissional, este também está relacionado ao aspecto financeiro, pois fica difícil você realmente equilibrar esse aspecto.". Contudo, alguns docentes federais e estaduais com mais de 15 anos de docência avaliam satisfatoriamente suas condições salariais e profissionais.

Costa et al., (1996, p.20) afirmam ainda, que "[...] o monopólio da formulação de discursos implica em exercer uma influência eficaz, embora invisível e silenciosa sobre as pessoas". Já Wanderley (1992) manifesta que refletir sobre o compromisso docente passa pela análise do significado do ensinar e aprender, incluindo a relação sujeito e objeto, a relação teoria e prática, a distinção entre conhecer e saber, o acompanhamento e participação na aceleração das mudanças e a relação entre cultura e linguagem.

O ambiente acadêmico e o clima institucional vêm sendo continuamente marcados pela competitividade exagerada, que gera individualismo, forma guetos acadêmicos e dificulta o crescimento coletivo, como aponta o Participante 2 que "[...] as pessoas são muito competitivas e todos têm essa visão de que o trabalho é muito individualista, e não conseguem trabalhar em grupo, [...] a competitividade pode ocorrer, mas ela pode ser coletiva e não precisa ser apenas individual". 
A competitividade e o individualismo são provocados pela introdução da lógica de mercado na lógica de produção de conhecimento, principalmente na manutenção financeira da universidade, como demonstra o Participante 7: "[...] a exploração [da docência universitária] tem aumentado muito com esse excesso de produtivismo que a universidade colocou, e que gerou uma competitividade, uma competição muito grande [...]". Ianni (1986, p. 41) ao discutir os dilemas presentes na atuação docente universitária, considera que "[...] nessa nova organização, o capital industrial, o grande capital, tomou conta da sociedade numa escala surpreendente [...], esse predomínio do capital tomou conta do Estado e influenciou amplamente a cultura lato sensu e a própria universidade".

Os objetivos da universidade pública deveriam ser desvinculados do interesse mercadológico e direcionados às demandas da coletividade, da gratuidade e da autonomia na produção do conhecimento, tentando romper ações externas e internas que impõe à universidade a lógica do capital, sendo necessário tornar a academia, segundo o Participante 13, um "[...] espaço de interesse coletivo, que de longe não é um espaço gratuito de formação profissional [...], onde a universidade deve ser destituída do interesse mercadológico [...]". Bunge (1980) aponta que as influências do modo econômico sobre a produção de conhecimentos provocam o descrédito da instituição universitária pela incompatibilidade deste processo, pois a busca pela autonomia de seu saber socialmente legitimado conflita com seu custeamento que a torna refém das diretrizes de mercado. Bunge (1980) analisa ainda, que neste processo a universidade não tem conseguido produzir conhecimentos suficientes para provocar mudanças no sistema econômico em favor da coletividade.

Com base na técnica do espelho, os discursos majoritários e minoritários relevantes ao estudo foram convertidos em categorias que buscam representar a relação entre o produtivismo e suas conseqüências ao ensino superior em Educação Física, como podem ser observadas na Figura 2, exposta a seguir. 


\begin{tabular}{|l|l|}
\hline Discurso Real & Discurso Ideal \\
\hline Competitividade & Cooperatividade \\
\hline Individualismo & Coletivismo \\
\hline Status acadêmico em desvalorização & Status acadêmico valorizado \\
\hline Condições salariais desfavoráveis & Condições econômicas favoráveis \\
\hline Ambiente acadêmico competitivo & Ambiente acadêmico cooperativo \\
\hline Fatores mercadológicos & Fatores acadêmicos \\
\hline Objetivos universitários econômicos & Objetivos universitários sociais \\
\hline a: Retirado da realidade; ' : Baseado na literatura.
\end{tabular}

Figura 2: Quadro-síntese das categorias reais e ideais associadas ao produtivismo na docência universitária.

\subsection{Afastamento entre teoria e pRÁtica}

A partir das análises de conteúdo sobre os resultados verbais dos participantes, foram identificados aspectos que provocam o afastamento entre o discurso real e o ideal, tais como as condições da formação em Educação Física, a carência de sólida fundamentação teórica, as atitudes e comportamentos individuais, os fatores sociais e econômicos, as exigências institucionais do ensino superior, e a dicotomia entre teoria e prática revelada pela contradição entre o ideal e o real e pela fraca incorporação da teoria à prática cotidiana.

A qualidade da formação em Educação Física está relacionada à preocupação sobre as insatisfatórias condições estruturais, físicas, pedagógicas e metodológicas que sustentam a formação nos diversos níveis desta área, desde a graduação até o doutoramento. Este posicionamento pode ser observado na fala da Participante 2 que "falta estrutura técnico-administrativa, [...] falta estrutura dos laboratórios, falta computadores, falta espaço físico [...]" e na fala do Participante 6 que "[...] existe esta contradição, essa dicotomia do biológico com pedagógico, [...] nunca vi nenhuma área evoluir, principalmente em termos de pesquisa de ponta, trabalhando somente com um ponto de vista $[\ldots] "$. Entretanto, os docentes com mais de 15 anos de docência, consideram estas condições satisfatórias ao seu trabalho.

Lemos (2010) destaca que o produtivismo tem provocado perda 
progressiva da autonomia universitária, desqualificação do público, fragmentação nos graus de ensino e de carreira, e sucateamento das universidades públicas e, Lampert (2010) salienta que a insuficiência de recursos destinados à universidade pública afeta as estruturas administrativas e pedagógicas desta instituição. Já Sobral e Ramos (2010) analisam que a racionalidade liberal atrela a práxis docente ao conceito de produtividade, num contexto contraditório de deterioração salarial e precarização das condições de trabalho.

A carência de uma fundamentação teórica que contemple conhecimentos sólidos é justificada pela necessidade de entender que os conhecimentos que sustentam a formação em saúde na Educação Física não devem estar desvinculados da prática cotidiana, como afirma o Participante 15:

[...] ainda falta um discurso mais fundamentado, pois existe um grupo de profissionais que está lidando com essa questão, mas a grande parte dos que está diante do público-alvo está mais no nível de praticar exercícios físicos do que possuir um discurso que realmente convença o praticante, apenas de execução [...].

Estudos têm demonstrado que as imposições mercadológicas provocam prejuízos à formação acadêmica, tais como, formação universitária prioritariamente voltada ao trabalho, exclusão da extensão e da pesquisa, ingerência e alienação crítica e política dos docentes, aceleração da qualificação stricto sensu e fragmentação do trabalho e reprodução de conhecimentos entre outras (PINTO, 2000; LEMOS, 2010; MARQUES, PINTO, 2010). Portanto, a carência de uma sólida fundamentação teórica pode ser considerada, além de um efeito, como uma causa eficiente na manutenção do produtivismo econômico e acadêmico.

As atitudes e comportamentos individuais aumentam o distanciamento entre teoria e prática à medida que, apesar dos saberes inerentes ao professor do ensino superior, são identificadas características pessoais que extrapolam os conhecimentos adquiridos, como demonstra o Participante 9 que "[...] o discurso que vai além daquilo que na prática acontece $[. .$.$] , na realidade existe um descompasso entre$ 
aquilo que se sabe, até pelo fato de se atuar no ensino superior, e aquilo que na realidade acontece [...]". Sobral e Ramos (2010) apontam que um dos sustentáculos do produtivismo é o individualismo, que influencia toda individualidade e coletividade humana.

Os fatores sociais e econômicos impõem condições financeiras insuficientes à docência no ensino superior. Contudo, os professores entendem que ainda assim deveria existir uma coerência entre o saber e o fazer, já que o docente do ensino superior está exposto às dificuldades pessoais e profissionais atuais da maioria das profissões, como indica o Participante 1:

[...] mesmo vivendo a realidade de um profissional ou intelectual mal remunerado, ele [Docente] deveria por uma questão de conhecimento que tem, deveria fazer, porque é bom para a saúde dele, é coerente com o trabalho dele, e para ele sentir que ele está fazendo uma coisa coerente [...].

Fernandes $(1998$, p.1) analisa que o ofício de professor sofre diversas tensões transformativas e demonstra que este profissional, apesar de ser um componente ativo, está sujeito a todas as vicissitudes do mercado de trabalho, como qualquer outro trabalhador. Já Wanderley (1992) considera que o compromisso docente na universidade, exige a análise da situação que determina muito do sentido do seu cotidiano e de suas práticas, e fornece indicativos sobre a maneira como o docente constrói o seu mundo.

As exigências institucionais provocam dificuldades na produção científica de conhecimentos em saúde, principalmente por ser uma instituição social que não se apresenta saudável. Os participantes entendem que a universidade explora seus técnicos e professores, não oferece condições de trabalho, admite preconceitos tais como sexismos e racismos, e ainda cobra uma formação profissional de docentes que nem sempre são sadios. Este processo poderá formar futuros profissionais expostos a estes agravos, como demonstra o Participante 14:

[...] há um exagero, uma descontextualização do significado do que seja promover saúde, [...] na prática de atividades físicas no ensino superior público existe uma contradição. [...] É uma incongruên- 
cia entre teoria e prática [...]. Podemos ver professores que promovem a saúde, mas, não são exemplos do que eles dizem o que é saúde [...].

Estudos realizados por Júnior, Sguissardi e Silva (2010) demonstram que docentes de universidades estatais públicas apesar de aparentemente possuírem percepções positivas e de aceitarem seu trabalho, apresentam graves contradições, pois relatam diversos problemas de saúde, tais como depressão, distúrbio de humor e de sono, entre outros. Portanto, verifica-se que as exigências institucionais provocadas pelo produtivismo universitário, podem, no caso da formação Educação Física, gerar graves consequências não só à saúde individual, mas também coletiva.

O distanciamento entre teoria e prática é inerente à atuação em Educação Física e saúde, pois a prática, por tratar-se do real, é dinâmica e, portanto, susceptível às vicissitudes humanas, enquanto que a teoria é estática por pretender-se ideal. O Participante 1 aponta a existência da contradição na prática, pois a Educação Física "[...] enquanto grupo de intelectuais, enquanto instituição, enquanto ciência do movimento humano, tem um discurso de que a atividade física é boa para a saúde, mas na prática os intelectuais não realizam. É um paradoxo, é uma contradição, e isto é um fato.". Fensterseifer (2009), ao analisar os problemas existentes na prática pedagógica em Educação Física, afirma que existe um "[...] agravante de uma histórica dicotomia entre teoria e prática, encarnada na noção de 'atividade' [fazer pelo fazer], e em processos de formação centrados em aspectos técnico-instrumentais" (FENSTERSEIFER, 2009, p.210).

A contradição entre o ideal e o real passa a ser entendida como parte do ser humano e provoca uma busca constante de aproximação entre a prática e o discurso, como afirma o Participante 7 que "[...] na verdade a grande essência do ser humano é a contradição [...], nada deve ser idealizado [...], pois se for idealizado, você cria um preconceito em respeito àquilo [...], então existe esta necessidade de reflexão, de dar uma reviravolta e aproximar a prática do discurso [...]". Fensterseifer (2009), ao analisar a Educação Física como prática pedagógica normativa, demonstra que as verdades que sustentam esta área não se 
limitam ao ser, mas, envolve um dever ser, posicionando assim, a linguagem como centro do processo de validação do conhecimento através dos significados inerentes aos conteúdos. Roldão (2007) discutindo a formação docente, afirma ainda que a relação teoria-prática carrega uma conceitualização simbólica, a qual pode ser pouco operativa e ocultar a íntima dependência de um campo diante do outro.

A fraca incorporação da teoria à prática cotidiana pode provocar o descrédito social de conhecimentos que deveriam melhorar a vida humana, como observa o Participante 5, que entende que "[...] o discurso parece que não é fruto da nossa própria prática, mas algo que incorporamos da literatura, e repassamos para os outros nos colocando como exemplos desse discurso [...]" e que poderá pela repetição "[...] até enfraquecer esse discurso e entrar em descrédito, porque nós não convencemos nossos interlocutores pela fragilidade desse nosso discurso." Segundo Costa et al., (1996), as análises sobre a docência universitária apontam que ainda existem pontos problemáticos em seu interior, como por exemplo, o controle político tanto da ação como do discurso, a autoridade do conhecimento científico e, o descrédito à produção dos conhecimentos socialmente desejáveis.

Com base na técnica do espelho, os discursos majoritários e minoritários relevantes ao estudo, foram convertidos em categorias que buscam representar o afastamento entre os discursos real e ideal na formação em Educação Física, as quais podem ser observadas na Figura 3, exposta a seguir.

\begin{tabular}{|l|l|}
\hline Discurso Real & \\
\hline Condições estruturais negativas & Discurso Ideal $^{\mathbf{b}}$ \\
\hline Fundamentação teórica pouco sólida & Condições estruturais positivas \\
\hline Atitudes divergentes da teoria & Fundamentação teórica sólida \\
\hline Condutas divergentes da teoria & Atitudes convergentes à teoria \\
\hline Fatores sócio-econômicos negativos & Condutas convergentes a teoria \\
\hline Instituição universitária doente & Fatores sócio-econômicos positivos \\
\hline Fraca incorporação teórica à prática & Instituição universitária sadia \\
\hline
\end{tabular}

a: Retirado da realidade; b: Baseado na literatura.

Figura 3: Quadro-síntese das categorias reais e ideais associadas ao afastamento entre teoria e prática. 


\subsection{APROXIMAÇÃO ENTRE TEORIA E PRÁTICA}

A partir das análises de conteúdo sobre os resultados verbais dos participantes, foram identificados aspectos que propiciam a aproximação entre o discurso real e o ideal, principalmente os que permitem superações ao entendimento de saúde, às orientações paradigmáticas, às bases legais e empíricas da atuação docente, tais como a ampliação do conceito de promoção de saúde para educação em saúde, as mudanças teóricas e paradigmáticas necessárias à Educação Física, a consciência sobre o papel do discurso na formação universitária e sobre o conhecimento docente em Educação Física.

Não desconsiderando as bases biológicas hegemônicas inerentes à saúde, pode-se entender que a possibilidade de ampliação do conceito de promoção da saúde deve, mesmo de maneira dicotômica, necessariamente introduzir as questões políticas e sociais, avançando as discussões centradas nos aspectos unicamente orgânicos, como entende o Participante 3: "A saúde é determinada pelo contexto político-social, ela chega na vida das pessoas, não dá para abrir mão das dimensões biológicos e comportamentais das pessoas, mas essas dimensões são orientadas, determinadas pelo contexto social $[\ldots]^{\prime \prime}$.

Paim e Almeida Filho (1998) analisam que as mudanças científicas e sociais ocorridas desde o século $\mathrm{XX}$ vêm exigindo reformulações no conceito de saúde que afetam diversas áreas. Mendes e Nóbrega (2008) demonstram que a apropriação do conceito de saúde pela Educação Física brasileira, surgiu com a visão médico-higienista do final do século XIX e início do século XX, e que ainda afeta esta área. Portanto, pode-se sugerir que a ampliação do conceito de saúde não é apenas uma necessidade em Educação Física, mas uma superação essencial a esta área.

A possibilidade de mudanças teóricas e paradigmáticas em Educação Física deve admitir a existência das diferentes correntes do conhecimento científico, não negligenciando ou discriminando as vertentes existentes, como demonstra o Participante 5 que "[...] a 
Educação Física tem que repensar o discurso, [...], pois o discurso deve sempre mostrar o ideal [...], mas também o processo de mudança enfatizando como que eu mudo os hábitos de vida [...]", e o Participante 12: "o discurso da saúde na Educação Física deveria ser direcionado, exclusivamente para uma perspectiva de educação para saúde. E educação no sentido de emancipar as pessoas [...], para conquistar a sua condição de saúde.".

Segundo Fensterseifer (2009), a superação do modelo científico hegemônico e a conseqüente aceitação e coexistência de diferentes paradigmas em Educação Física, pode contribuir para diferentes modos de se produzir conhecimentos científicos e permitir um melhor conhecimento da complexidade humana. Contudo, esta pluralidade científica não deve ser entendida como uma forma de aceitação de abusos metodológicos que não respeitam as especificidades inerentes à pesquisa e ao pesquisado.

A superação do distanciamento entre teoria e prática pode ser conquistada através da consciência sobre o papel do discurso na formação universitária, sendo que o docente deve ser autônomo e ter controle sobre suas atitudes e ações. Além disso, o professor não pode esquecer-se da força que o discurso oferece, buscando deste modo, a manutenção da legitimidade de seu discurso, para que este não caia no descrédito social, como observa o Participante 4:

$\mathrm{O}$ próprio profissional tem que ter um discurso coerente com a sua prática. Então se prega o benefício da atividade física e saúde ele tem que ser uma pessoa que busca por ele mesmo promover a sua própria saúde, de gerenciar a sua saúde, nada mais é do que controlar suas atividades físicas.

Estudos apontam que a consideração da normatividade e a superação do apenas fazer, pode possibilitar uma prática pedagógica que avance à reprodução de conhecimentos e contribua para transformação social (FENSTERSEIFER, 2009; ROLDÃO, 2007). Contudo, não se pode negligenciar que existem determinadas condições que podem gerar o descrédito da produção de conhecimento científico e tecnológico, principalmente aquelas associadas à lógica 
mercadológica, como por exemplo, a dominação dos aspectos econômicos sobre as questões éticas (COSTA et al., 1996).

A possibilidade de aproximação entre o discurso pessoal e o discurso teórico pode ocorrer para além do que realmente o sujeito realiza. No entanto, este posicionamento não deve ser entendido como manipulação de informações, já que alguns sujeitos salientam este cuidado necessário à pesquisa científica. Esta consciência oferece consistência e confiabilidade à análise do trabalho docente, como afirma o Participante 9 que "[...] uma coisa que acontece muito nas pesquisas, e que se tem que tomar cuidado, é que muitas respostas estão em torno de um ideal, daquilo que tu acha que realmente é certo, e não daquilo que realmente faz no dia-a-dia [...]".

Com base na técnica do espelho, os discursos majoritários dos participantes e minoritários relevantes ao estudo, foram convertidos em categorias que buscam representar a aproximação entre os discursos real e ideal na formação em Educação Física, como podem ser observadas na Figura 4, exposta a seguir.

\begin{tabular}{|l|l|}
\hline${\text { Discurso } \text { Real }^{\mathbf{a}}}$ & Discurso Ideal $^{\mathbf{b}}$ \\
\hline Saúde sob enfoque orgânico & Saúde sob enfoque sócio-político \\
\hline Hegemoneidade paradigmática & Pluralidade paradigmática \\
\hline Vulgarização do discurso em saúde & Relevância do discurso em saúde \\
\hline Legalidade do discurso em saúde & Legitimidade do discurso em saúde \\
\hline Bases empíricas da atuação docente & Bases científicas da atuação docente \\
\hline
\end{tabular}

a: Retirado da realidade; b: Baseado na literatura.

Figura 4: Quadro-síntese das categorias reais e ideais associadas à aproximação entre teoria e prática.

\section{ConSIDERAÇõES FINAIS}

Considerando que os participantes deste estudo são doutos professores, pode-se constatar a consciência sobre o papel docente na relação entre a realidade cotidiana e a idealidade inerente à teoria. Entretanto, deve-se apontar que a maioria das temáticas tratadas neste estudo é de conhecimento corrente dos sujeitos e que as características de liberdade de pensamento e autonomia nas ações são acentuadas na docência do ensino superior. Portanto, a partir do 
posicionamento cuidadoso sobre os conhecimentos e os valores envolvidos nesta pesquisa, tanto inerentes aos pesquisados quanto ao pesquisador, pode-se concluir que a docência universitária relaciona-se ao produtivismo acadêmico a partir da competitividade e do individualismo acadêmicos que afetam o status docente, o ambiente acadêmico, os objetivos institucionais e a legitimidade da universidade. Pode-se concluir ainda, que os aspectos que distanciam o discurso real do discurso ideal predominam sobre os aspectos que os aproximam, principalmente no início da carreira acadêmica. Os aspectos que afastam o discurso real do discurso ideal referem-se às condições da formação em Educação Física, à carência de sólida fundamentação teórica, às atitudes e comportamentos individuais, aos fatores sociais e econômicos, às exigências institucionais do ensino superior e à dicotomia entre teoria e prática, enquanto que os aspectos que aproximam o discurso real do discurso ideal referemse às superações necessárias ao conceito de saúde, à diversidade paradigmática e às características da própria atuação docente.

The real discourse and the ideal discourse of
Physical Education professors on teaching
Abstract: The present study aimed to analyze the
relationship between the real discourse and the ideal
discourse of physical education professors on
teaching, from public universities of the State of Santa
Catarina, Brazil. The participants were selected
according to criteria related to the subjects and the
institutions, with a total of 16 out of the 27 individuals
that were initially identified. The data were collected
through semi-structured and recurring interviews and
analyzed using content analysis. There was a
predominance of the aspects that move the ideal
discourse away from the real discourse, especially
those related to productivism, such as competiveness,
individualism, devaluation, unfavorable conditions,
competitive environments, market factors and
economic objectives.
Keywords: Faculty. Physical Education and training.
Higher education.

Vovimento, Porto Alegre, v. 16, n. 03, p. 133-154, julho/setembro de 2010. 


El discurso real y el discurso ideal de
profesores universitários de Educación Física
sobre la enseñanza
Resumen: El presente estudio tuvo como objetivo
analizar la relación entre el discurso real y el discurso
ideal de los profesores de educación física del ámbito
universitario sobre la enseñanza, de universidades
publicas del Estado de Santa Catarina, Brasil. Los
participantes fueron seleccionados a través de
criterios relativos a las personas y a las instituciones,
totalizando 16 de los 27 individuos identificados previ-
amente. Los datos fueron recogidos mediante entre-
vistas semiestructuradas y recurrentes, y analizados
a través de análisis de contenido. Fue verificado un
predominio de los elementos que distancian el discur-
so ideal del discurso real, en especial aquellos
asociados con la alta productividad, tales como
competitividad, individualismo, desvalorización,
condiciones desfavorables, ambientes competitivos,
factores de mercado y metas económicas.
Palabras-clave: Docentes. Educación y
Entrenamiento Físico. Educación Superior.

\section{REFERÊNCIAS}

ALVES-MAZZOTTI, A. J.; GEWANDSZNAJDER, F. O método nas ciências naturais e sociais: pesquisa quantitativa e qualitativa. 2.ed. São Paulo: Pioneira Thomson Learning, 2002.

ANDRADE, A. Desenvolvimento de uma técnica de pesquisa qualitativa para uso em psicologia do esporte: a técnica do espelho. In: CONGRESSO DE STRESS DA ISMA, 3. 2003, Porto Alegre. Anais..., Porto Alegre: ISMA Brasil, 2003. p. 50-50.

BARDIN, L. Análise de conteúdo. Lisboa: Edições 70, 2000.

BIANCHETTI, L. 30 anos do colégio brasileiro de ciências do esporte: os desafios para uma associação científica e os dilemas dos intelectuais institucionalizados. Revista Brasileira de Ciências do Esporte, Campinas, v. 30, n. 3, p. 13-30, mai. 2009.

BUNGE, M. Ciência e desenvolvimento. São Paulo: EDUSP, 1980.

CHAUÍ, M. Escritos sobre a universidade. São Paulo: EDUNESP, 2001.

COSTA, F. C. et al. Formação de professores em Educação Física: concepções, investigação, prática. Portugal: FMH, 1996. 
DE TOMASI, L.; WARDE, M. J.; HADDAD, S. O banco mundial e as políticas educacionais. São Paulo: Cortez, 1998.

FENSTERSEIFER, P.E. Epistemologia e prática pedagógica. Revista Brasileira de Ciências do Esporte, Campinas, v. 30, n. 3, p. 203-214, mai., 2009.

FERNANDES, R. Ofício de professor: O fim e o começo dos paradigmas. In: SOUSA, C. P.; CATANI, D.B. Práticas educativas, culturas escolares, profissão docente. São Paulo: Escrituras, 1998.

IANNI, O. O professor como intelectual: Cultura e dependência. In: CATANI, D. B. et al. Universidade, escola e formação de professores. São Paulo: Brasiliense, 1986.

LAMPERT, H. Repensando a universidade: algumas notas para análise. Universidade e Sociedade, Brasília, n. 45, p. 103-112, jan. 2010.

LAVILLE, C.; DIONNE, J. A construção do saber: manual de metodologia da pesquisa em ciências humanas. Porto Alegre: Artes Médicas, 1999.

LEMOS, D. Alienação no trabalho docente? O professor no centro das contradições. Universidade e Sociedade, Brasília, n. 45, p. 27-38, jan., 2010.

MARQUES, E. P.; PINTO, M. B. Universidade e precarização: considerações sobre o processo de trabalho dos servidores da UFF. Universidade e Sociedade, Brasília, n. 45, p. 39-50, jan., 2010.

MARTINS, A. L. M. A marcha do "capitalismo universitário" no Brasil nos anos 1990. Avaliação, Campinas-Sorocaba, v. 13, n. 3, p. 733-743, nov., 2008.

MENDES, M. I. B. S.; NÓBREGA, T. P. Brazil-Médico e as contribuições do pensamento médico-higienista para as bases científicas da educação física brasileira. História, Ciências, Saúde - Manguinhos, Rio de Janeiro, v. 15, n. 1, p. 209-219, jan./mar., 2008.

MOREIRA, E. C.; TOJAL, J. B. A. G. A formação em Programas de Pós-Graduação Strictu Sensu em Educação Física: preparação docente versus preparação para pesquisa. Movimento, Porto Alegre, v. 15, n. 4, p. 127-145, out./dez., 2009.

PAIM, J. S.; ALMEIDA FILHO, N. Saúde coletiva: uma "nova saúde pública" ou campo aberto a novos paradigmas? Revista de Saúde Pública, São Paulo, v. 32, n. 4, p. 299-316, jun. 1998.

PINTO, M. B. A subordinação do trabalho docente à lógica do capital. Outubro, São Paulo, n. 4, p. 17-24, out. 2000.

RABELO, C. D. As feições neopragmáticas do PROFA: formação docente para a lógica produtivista? Revista Eletrônica Arma Crítica, Fortaleza, n. 2, p. 147162, mar. 2010. 
ROLDÃO, M. C. Função docente: natureza e construção do conhecimento profissional. Revista Brasileira de Educação, Rio de Janeiro, v. 12, n. 34, p. 94-103, jan./abr. 2007.

SGUISSARDI, V. O Desafio da Educação Superior no Brasil. Quais são as perspectivas? Avaliação, Campinas-Sorocaba, v. 5, n. 2, p. 7-24, jun. 2000.

SILVA JÚNIOR, J. R. O professor pesquisador nas universidades públicas no contexto da internacionalização do capital: a produtividade do trabalho imaterial superqualificado. Revista Portuguesa de Educação, Braga, v. 22, n. 1, p. 145177, 1. sem. 2009.

SILVA JÚNIOR, J. R; SGUISSARDI, V.; SILVA, E. P. Trabalho intensificado na universidade pública brasileira. Universidade e Sociedade, Brasília, n. 45, p. 9-26, jan. 2010.

SILVA, R. Características do estilo de vida e da qualidade de vida de professores do ensino superior público em educação física. 2006. 264f. Tese (Doutorado em Engenharia de Produção)-Centro Tecnológico, Universidade Federal de Santa Catarina, Florianópolis, 2006.

SINGER, P. Poder, política e educação. Revista Brasileira de Educação, Rio de Janeiro, n. 1, p.5-15, jan./abr. 1994.

SMALING, A. The argumentative quality of the qualitative research report. International Journal of Qualitative Methods, Edmonton, v. 1, n. 3, p. 1-15, summer 2002.

SOBRAL, E.; RAMOS, S. R. A "noite da desatenção" na cidade do conhecimento: os significados ético-políticos do produtivismo no cotidiano acadêmico. Universidade e Sociedade, Brasília, n. 45, p. 9-26, jan. 2010.

WANDERLEY, L. E. W. Compromissos filosóficos e políticos do docente. In: D'ANTOLA, A. A prática docente na universidade. São Paulo: EPU, 1992.

ZANELLI, J. C. Pesquisa qualitativa em estudos da gestão de pessoas. Estudos de Psicologia, Natal, v. 7, (Número Especial), p. 79-88, 2002. 